\title{
Northward and Northwestward Propagation of 30-60 Day Oscillation in the Tropical and Extratropical Western North Pacific
}

\author{
Chih-Hua TSOU, Pang-Chi HSU \\ Department of Earth Sciences, National Taiwan Normal University, Taipai, Taiwan \\ Wen-Shung KAU and Huang-Hsiung HSU \\ Department of Atmospheric Sciences, National Taiwan University, Taipei, Taiwan
}

(Manuscript received 25 June 2004, in final form 26 May 2005)

\begin{abstract}
This study investigates the northward, and northwestward propagation of 30-60 day oscillation over the western North Pacific (WNP) at upper, and low levels with a three-dimensional streamfunction tendency equation. In the tropical WNP, the surface frictional effect associated with the cyclonic circulation enhances the low-level convergence at the cyclonic vorticity center to the northwest of the convection, causing the 30-60 day convection to develop northwestward. The vorticity advection induces the 30-60 day circulation at upper and low levels to propagate northwestward, with a baroclinic structure. The combined effect of surface frictional-diabatic heating, and vorticity advection, causes the 30-60 day convection and circulation to develop and propagate simultaneously northwestward. After the convection fully develops, increased static stability, associated with adiabatic cooling, reduced solar radiation due to the cloud-radiation effect, and negative land-surface feedbacks on moisture availability, restrict any further development of the 30-60 day convection.

A wave train emanating from the South China Sea/western North Pacific (SCS/WNP) into the extratropical North Pacific, is well established 15-days after the convection reached maximum intensity over the SCS/WNP. The main process and mechanism responsible for the northwestward propagation of this 30-60 day oscillation in the extratropical WNP is similar to the process proposed for the tropical WNP, except that in the mid-latitudes where the coriolis parameter becomes large, the influence of upper-level vorticity advection extends down to the low levels.
\end{abstract}

\section{Introduction}

The onset of the Asian Summer Monsoon is characterized by an abrupt change in largescale circulation, and the sudden enhancement of heavy precipitation. Other than the seasonal cycle, Intraseasonal Oscillation (ISO) has been suggested to play an important role in the abrupt changes of the Indian and Asian Sum-

Corresponding author: Chih-Hua Tsou, Department of Earth Sciences, National Taiwan Normal University, Taipei, Taiwan.

E-mail: chi@cc.ntnu.edu.tw

(C) 2005, Meteorological Society of Japan mer Monsoon (e.g., Yasunari 1981; Krishnamurti and Subrahmanyam 1982; Lau and Chan 1986; Chen and Chen 1995). To improve seasonal forecast of the heavy precipitation associated with the monsoon, one may need to understand the characteristics and mechanisms responsible for the development and propagation of the ISO. However, the propagation of ISO is somewhat complicated during the summer. Examining the 40-50 day oscillation of divergent circulation during the summer of 1979, Krishnamurti et al. (1985) noted that the divergent center over the Indian Ocean propagated northward. Based on the one-point corre- 
lation pattern, Lau and Chan (1986) found that in the boreal summer, OLR (Outgoing Longwave Radiation) anomalies propagate eastward and northward simultaneously in the Indian Ocean. Over the western North Pacific (WNP) and South China Sea (SCS), northward and northwestward propagation are found (Lau and Chan 1986; Chen and Murakami 1988).

Why does the 30-60 day oscillation change the direction of propagation over the Asian Monsoon prevailing region from winter to summer? Several numerical and observational studies on the atmospheric internal dynamics and land-air-sea interaction have been made to address this question (e.g., Webster 1983a; Goswami and Shukla 1984; Kawamura et al. 1996; Chen at al. 2000). Using a zonal symmetric non-linear two layer model, containing a mixed layer ocean and a surface scheme model, Webster (1983a) found that the northward propagation of ISO in the Indian Monsoon region can exist in the model only when a full hydrology cycle is considered. Contrary to Webster's numerical experiments, the numerical simulation performed by Ferranti et al. (1999) showed that the northward propagation of ISO in the Indian Monsoon region could be simulated with or without land-atmosphere interactions. Ferranti et al. (1999) suggested that the northward propagation is primarily related to internal atmospheric dynamics.

Wang and Xie (1997) emphasized the role of moist static energy on the emanation and development of westward propagating Rossby waves over the Western Pacific (WP). Their numerical experiments revealed that the eastward propagating Kelvin-Rossby wave packet is disintegrated in the central eastern Pacific due to the reduction of moisture availability along with the mean sinking motion in the central eastern Pacific. When the decaying waves approach the western North Pacific, the high moist static energy supply, and mean upward motion of this region, further favors the emanation of the westward propagating Rossby waves. As the westward propagating Rossby waves reach Asian landmass, the numerical study by Wang and Xie (1997) is significantly different from the observation study by Hsu and Weng (2001). In the former numerical study, the Rossby waves continually intensify and propagate westward in the South Asian
Monsoon region. In the later observational study, the OLR anomalies weaken due to the lack of moisture supply from the ocean.

Surface moisture convergence to the north of convection has recently been proposed as an important factor to the northward movement of ISO (Kemball-Cook and Wang 2001; Hsu and Weng 2001; Lawrence and Webster 2002). Kemball-Cook and Wang (2001) attributed this surface moisture convergence to the air-sea interaction. They found that in the subsidence region north of convection, the downward shortwave radiation increases, and the latent heat flux decreases, causing the increase in sea surface temperature. As sea surface temperature increases, low pressure is induced and moisture is converged into the low pressure north of the convection. Lawrence and Webster (2002) suggested that this surface moisture convergence is induced by surface frictional convergence into the low pressure center embedded in a Rossby wave north of the deep convection. Jiang et al. (2004) provided a different interpretation of surface moisture convergence. They proposed that the generation of barotropic vorticity in the free atmosphere causes moisture convergence in the planetary boundary layer.

Although recent studies have emphasized the importance of surface moisture convergence to the northward propagation in the Indian Monsoon and Western Pacific regions, the relative importance of dry dynamic forcing, and diabatic heating effect to the northward propagation of the 30-60 day oscillation are still in debate. Most studies emphasize the propagation of the 30-60 day oscillation south of $20^{\circ} \mathrm{N}$, but fewer attempts have been made to explain the propagation of the 30-60 day oscillation in the western Pacific north of $20^{\circ} \mathrm{N}$. Kawamura et al. (1996) found that the tropical ISO may develop or propagate into the mid-latitude WNP. However, the mechanisms responsible for the propagation of this wave train after it is formed are not interpreted in their study. This study attempts to investigate and explain the development and propagation of ISO as they approach East Asia from the tropical and extratropical WNP. The ISO propagating northward from $20^{\circ} \mathrm{N}$ is particularly interesting in this study due to their relationship with the northward propagation of monsoon rainfall in East Asia 
(e.g., Chen and Chen 1995). The development and propagation of 30-60 day oscillation is investigated by a three-dimensional streamfunction tendency equation. Streamfunction tendency is chosen as the diagnostic tool, because it directly reflects the propagation and development of wave systems in the tropics and extratropics, and because it can estimate the relative importance of adiabatic and diabatic forcing mechanisms.

\section{Data and analysis procedure}

\subsection{Data and filtering}

The National Centers for Environmental Prediction (NCEP)/National Center for Atmospheric Research (NCAR) reanalysis data (Kalnay et al. 1996), and daily OLR analyzed from the Climate Diagnostic Center (Liebmann and Smith 1996) from 1979 to 1998 are used to examine circulation and convection, respectively. Both data sets are archived on a $2.5^{\circ} \times 2.5^{\circ}$ latitude-longitude grid. The other data sets adopted in this study are weekly Sea Surface Temperature (SST) from 1982 to 1998 produced by the NCEP/NCAR (Reynolds and Smith 1994). To extract the ISO signal, SST weekly data were linearly interpolated into daily data.

As the season changes from winter to summer, the ISO signal weakens. The oscillation period of ISO changes irregularly. To isolate the ISO signal from the original data, an orthonormal wavelet transform developed by

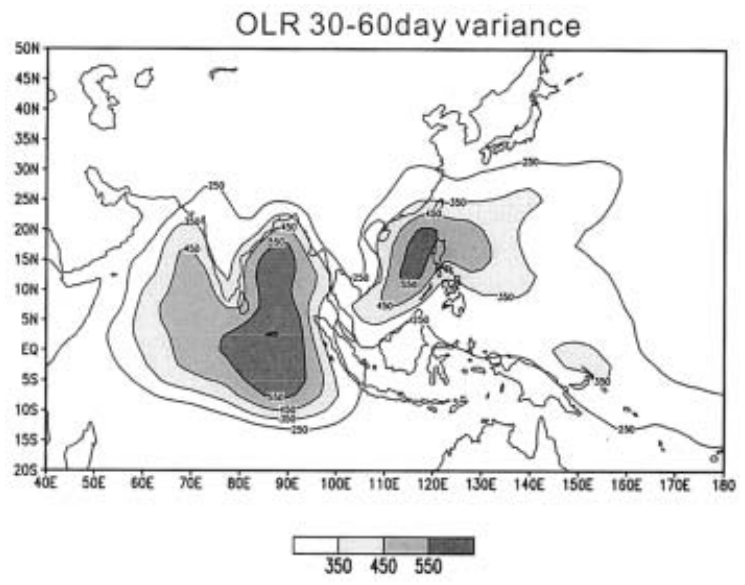

Fig. 1. May-July OLR variance distribution for climatology (1979-1998) due to 30-60 day oscillation.
Daubechies (1988) which has the capability of localizing signals both in time and frequency simultaneously, is adopted to extract the 30-60 day oscillation from the original data. The horizontal distribution of OLR variances due to 30-60 day oscillation averaged from May to July for climatology (1979-1998) is depicted in Fig. 1. There are three regions of high variance concentrated over the Indian Ocean, the Bay of Bengal, and the SCS/WNP (Fig. 1). The maximum variance of the 30-60 day OLR in East Asia occurs in the SCS.

\subsection{Lag-regression and phase compositing technique}

After filtering, regression analysis and phase compositing are applied in this study to investigate the convection and circulation of the 30-60 day oscillation during the northward/ northwestward propagation. Regression analysis is chosen as an analysis tool, because it can objectively identify the development and propagation of a wave system. However, the nonlinear part of development and propagation may be masked by the linear regression analysis. For this reason, compositing technique is used as a complementary method of studying the propagation of ISO.

The index used for lagged regressions is constructed from the time series of an areaaveraged $30-60$ day OLR at SCS $\left(110-120^{\circ} \mathrm{E}\right.$, $7.5-17.5^{\circ} \mathrm{N}$ ), where the maximum variance of the 30-60 day OLR occurs in East Asia. Based on the same index used in lag-regression, the life cycle of the 30-60 day oscillation is composed by a phase compositing technique similar to that of Hendon and Salby (1994). Each life cycle of the 30-60 day oscillation is divided into nine different phases. Phase 0 represents the time when the index reaches minimum value, i.e. when the strongest convection occurs over the SCS. In contrast, phases -4 and +4 indicate the nearest maxima before and after phase 0 , respectively. Phases -2 and +2 are the zero crossing time of 30-60 day OLR oscillation, before and after phase 0 . Phases $-3,-1,+1$, and +3 are the median values between phases -4 , $-2,0,+2$, and +4 , respectively. To avoid ambiguous signals, only those years that have at least one ISO peak amplitude greater than the climatological standard deviation are adopted for lagged regressions and phase compositing. 


\section{Streamfunction tendency equation}

\subsection{Formulation of streamfunction tendency equation}

Charney (1963) performed a scale analysis to investigate the large-scale motion in the tropics under the adiabatic conditions. Interestingly, he found that in the tropics, the fluctuation of pressure and temperature for the planetaryscale waves is one order of magnitude larger than that of synoptic-scale waves. If the diabatic heating rate does not exceed $5{ }^{\circ} \mathrm{C} /$ day, following the scale analysis by Charney (1963) and Webster (1983b), the vorticity and thermodynamic equation in isobaric coordinates for the planetary-scale waves over the entire globe can be expressed as:

$$
\begin{aligned}
& \left(\frac{\partial}{\partial t}+\vec{V} \cdot \nabla\right)(\zeta+f)+f \nabla \cdot \vec{V}=0 \\
& \frac{\partial T}{\partial t}=-\vec{V} \cdot \nabla T+\left(\frac{\sigma P}{R}\right) \omega+\frac{\dot{q}}{c_{p}}
\end{aligned}
$$

where $\vec{V}$ is horizontal wind vector; $\zeta$ is the relative vorticity; $f$ is the coriolis parameter; $T$ is the temperature; $P$ is the pressure; $c_{p}$ is the specific heat of dry air at constant pressure; $R$ is the dry air gas constant; $\omega$ is the vertical motion in isobaric surface; $\nabla$ is the horizontal del operator on an isobaric surface; $\dot{q}$ is the diabatic heating rate; and $\sigma=-\frac{R T}{P} \frac{\partial \theta}{\partial P}$ is the static stability.

A three-dimensional streamfunction for the planetary-scale waves over the entire globe can be obtained by first representing the vorticity tendency, divergence in Eq. (1), and temperature tendency in Eq. (2) as streamfunction tendency, $\omega$, and height tendency, respectively.

$$
\begin{aligned}
& \frac{\partial}{\partial t}\left(\nabla^{2} \psi\right)+\vec{V} \cdot \nabla(\zeta+f)=f \frac{\partial \omega}{\partial P} \\
& \frac{\partial}{\partial t}\left(\frac{\partial \phi}{\partial P}\right)+\frac{R}{P} \vec{V} \cdot \nabla T+\sigma \omega=-\frac{R}{P} \frac{\dot{q}}{c_{p}}
\end{aligned}
$$

where $\psi$ is streamfunction and $\phi$ is the geopotential height.

Eliminating the $\omega$ term in Eqs. (3) and (4), and rewriting the geopotential height tendency in Eq. (4) as the streamfunction tendency by quasi-geostrophic assumption, a threedimensional streamfuction for the planetaryscale waves over the entire globe can be derived as:

$$
\begin{aligned}
& {\left[\nabla^{2}+\frac{f^{2}}{\sigma} \frac{\partial^{2}}{\partial P^{2}}\right] \frac{\partial \psi}{\partial t}} \\
& \text { (A) } \\
& =-\vec{V} \cdot \nabla\left(\nabla^{2} \psi+f\right)-\frac{f R}{\sigma} \frac{\partial}{\partial P}\left(\frac{-\vec{V} \cdot \nabla T}{P}\right) \\
& \text { (B) } \\
& \text { (C) } \\
& -\frac{f \omega}{\sigma} \frac{\partial \sigma}{\partial P}-\frac{f}{\sigma} \frac{R}{c_{p}} \frac{\partial}{\partial P}\left(\frac{\dot{q}}{P}\right)
\end{aligned}
$$

Term (A) of Eq. (5) is the Laplacian of the streamfunction tendency. The forcing terms (B), (C), (D), and (E) are vorticity advection, differential thermal advection, differential heating, and vertical advection of static stability, respectively.

\subsection{Height tendency calculations}

To diagnose the vorticity tendency, the righthand side forcing mechanisms of Eq. (5) are calculated using NCEP/NCAR reanalysis data. The use of actual rather than geostrophic winds allows Eq. (5) to include both the rotational and divergent components of the winds. Diabatic heating is estimated from the thermodynamic energy equation. The pattern of diabatic heating calculated from NCEP/NCAR reanalysis data captures the gross features of the 30-60 day precipitation (not shown) in agreement with the wintertime results of Newman et al. (2000). Then, Eq. (5) is solved using the successive overrelaxation method (Tsou et al. 1987) with zero streamfunction tendencies at lateral, upper, and lower boundaries. The upper boundary is $100 \mathrm{mb}$, while the lower boundary is the first pressure level below the surface at each grid point. The vorticity tendencies are diagnosed at 24-hour intervals.

\section{Characteristics of northward propagation and development of the 30-60 day oscillation}

The propagation of 30-60 day oscillation is investigated by the lag-regression analysis. The positive lagged day indicates that the 30-60 day OLR at SCS proceeds the 30-60 day OLR of other regions. Figure 2 depicts the horizontal distribution of the lag regression coefficient between the index (30-60 day OLR at SCS), and the 30-60 day OLR, the 30-60 day vorticity, 

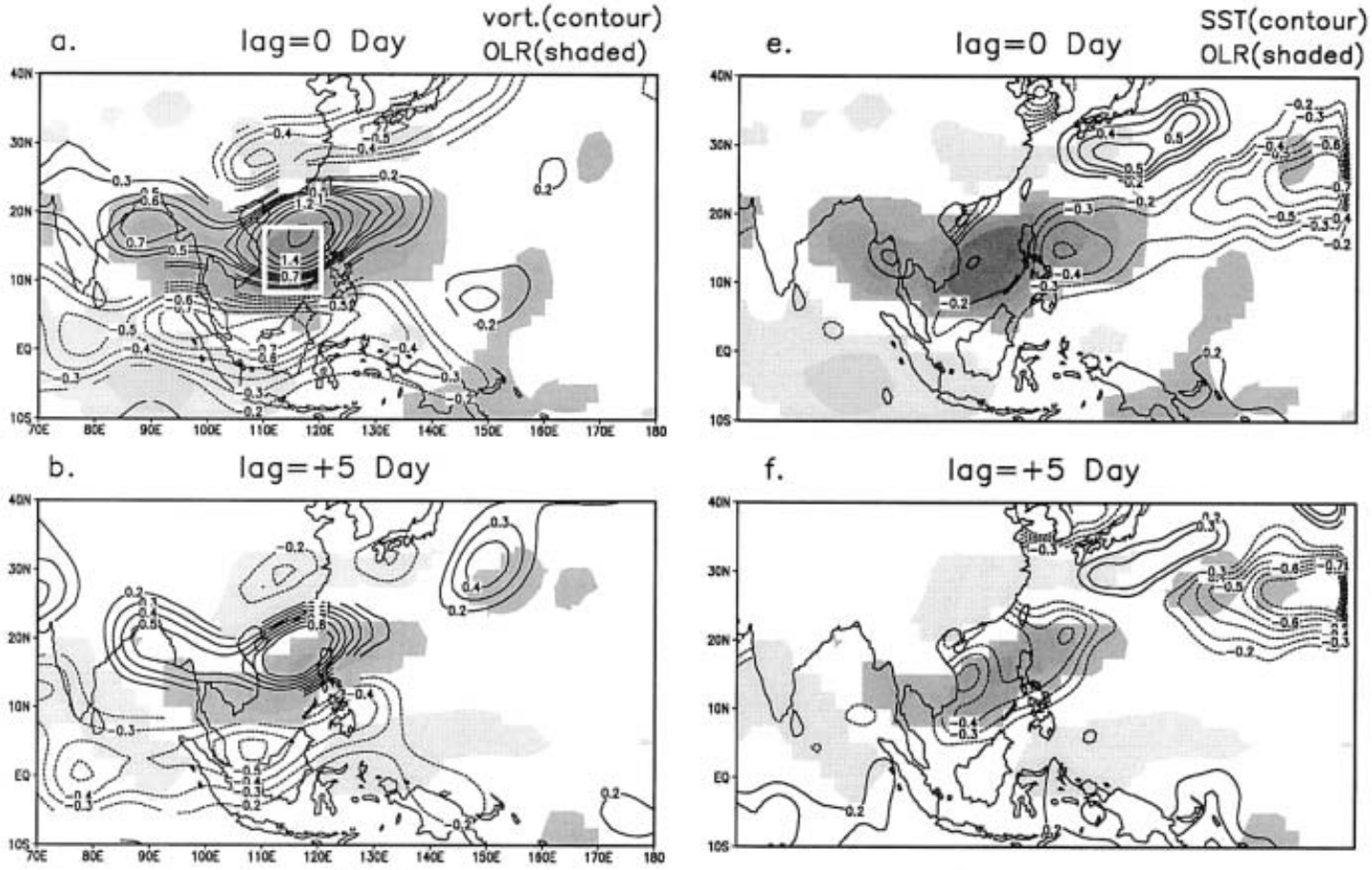

c.

$\operatorname{lag}=+10$ Day
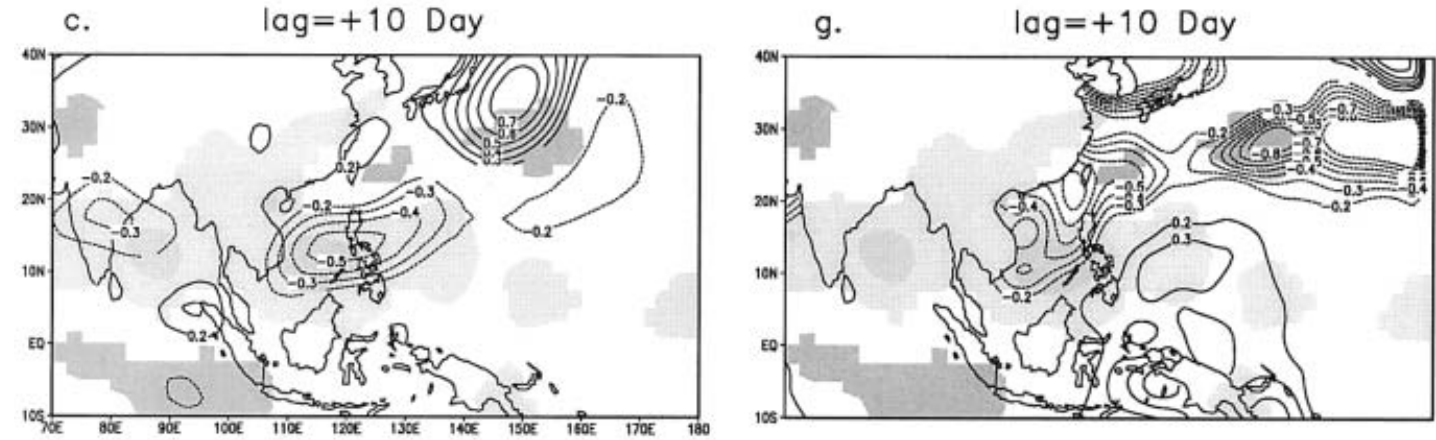

d.

$\operatorname{lag}=+15$ Day

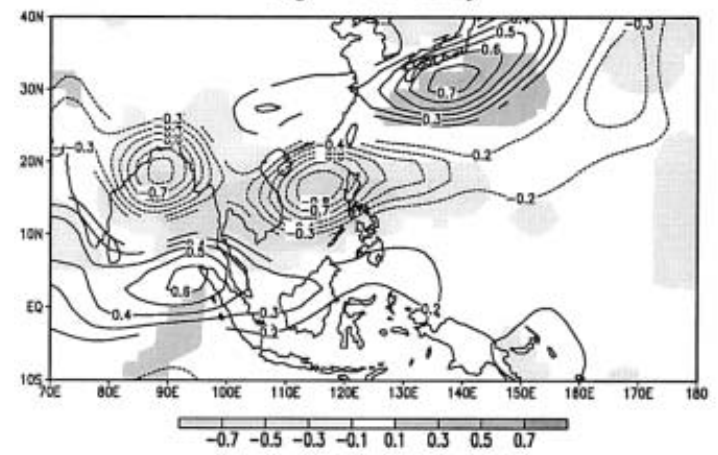

h.

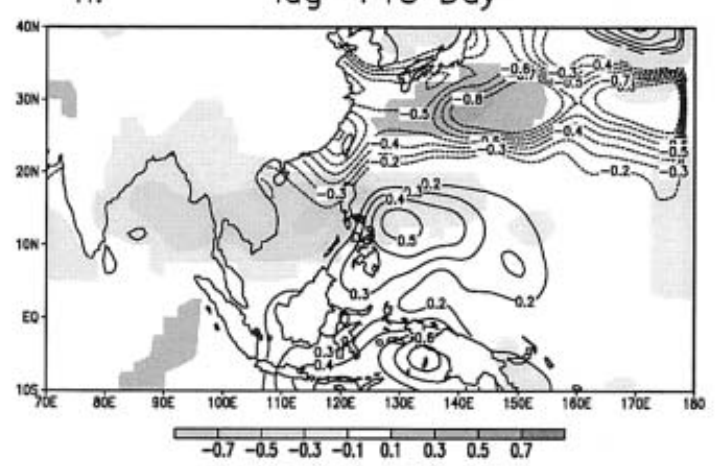

Fig. 2. Lag regression coefficients between the $30-60$ day OLR at SCS $\left(110^{\circ}-120^{\circ} \mathrm{E}, 7.5^{\circ}-17.5^{\circ} \mathrm{N}\right)$ and 30-60 day OLR (shaded) and 850-hPa vorticity (contoured) at lag (a) 0 day, (b) 5 day, (c) 10 day, and (d) 15 day. (e)-(h) same as (a)-(d), except contours for lag regression coefficients between the 30-60 day OLR at SCS and SST. Dark shades and solid lines indicate the positive regression coefficients, while light shades and dashed lines indicate the negative regression coefficients. The sign of OLR were changed for lag-regression. The regression coefficients that are significant at the 0.05 level are shaded or plotted. The box in (a) indicates the location of the index timeseries. 
and SST over the globe. For convenience, we change the sign of the index and OLR fields for lag-regression so that a positive correlation between the index and vorticity (SST) indicates convection associated with cyclonic vorticity (warm SST). The eastward propagation of the 30-60 day oscillations from the Indian Ocean to the Western Pacific prior to lag 0 day (not shown) has been thoroughly discussed in many studies (e.g., Hendon and Salby 1994). The present analysis would focus on the subsequent northward propagation.

At lag 0 day, a 30-60 day wave train, which may be generated by the mechanism proposed by Wang and Xie (1997), appears in the region from the equatorial Western Pacific to East Asia (Fig. 2a). The strongest 30-60 day convection extends from the SCS to the Western Pacific with a dry belt on its north and south sides (Fig. 2a). The center of cyclonic and anticyclonic vorticity is located on the northwest side of this strongest convection over the SCS/WNP and dry belt, respectively (Fig. 2a). This feature is similar to that in the theoretical study of Gill (1980). Such pattern distribution may be favorable to the subsequent northwestward development and propagation of the 30-60 day convection. During lag 0 day to lag 5 days (Figs. 2a and $2 \mathrm{~b}$ ), the 30-60 day convection over the SCS/WNP propagates northwestward but weakens after they reach maximum intensity over the SCS/WNP at lag 0 day (Fig. 2a). As the vorticity center reaches the land surface on lag 10 days, it dramatically weakens. This dissipation of vorticity is associated with the dissipation of convection (Fig. 2c). This feature is consistent with the observational study of Hsu and Weng (2001). The enhanced convection and cyclonic circulation over the SCS/WNP at lag 0 day is entirely alternated by the dry belt and anticyclonic circulation by lag +15 days (Fig. 2d). A region of positive OLR correlation appears in the Northwest Pacific south of Japan, while negative OLR correlation occurs in the SCS/WP (Fig. 2d). The wave structure at lag 15 days is similar to the wave structure at lag 0 day, but with the opposite sign.

The cloud-radiation feedback represented in Figs. $2 \mathrm{e}-\mathrm{h}$ is consistent with the observational study of MJO (Madden Julian Oscillation) by Lau and Sui (1997). 5-days after the enhanced convection occurs over the SCS/WNP, cool SST appears over most of the convection area at lag 5 days (Fig. 2f), while warm SST occurs north of the enhanced convection area, where the dry belt appears (Fig. 2f). Although the warm ocean surface to the northeast of the original convection in the Northwestern Pacific may favor the subsequent development of cyclonic circulation and convection, the 30-60 day convection does not develop in this warm ocean region, where the dry belt appeared (Fig. 2f). Instead the 30-60 day vorticity and convection redevelop in the North Pacific Ocean east of Japan at lag +5 days (Fig. 2f). During lag 5 to lag 15 days, the newly developed convection and vorticity enhance and propagate northwestward. As the new convection and vorticity enhance and propagate northwestward to the south of Japan at lag +15 days, the SST in the extratropical WNP cools down (Fig. 2h). In the extratropical WNP, the ocean may play a passive role in the development of the 30-60 day oscillation.

Figure 3 shows the lag regression coefficients between the 30-60 day OLR and the 30-60 day $200-\mathrm{hPa}$ vorticity and $850-\mathrm{hPa}$ vorticity at lag 15 day. It is interesting to note that a wave train emanating from the SCS into the extratropical North Pacific is well established at lag 15 days (Fig. 3). This indicates that the tropical ISO develops and propagates into the extratropical WNP 15-days after the original convection reaches maximum intensity over the SCS/WNP (Fig. 3). Such a feature is consistent with the results of Kawamura et al. (1996). Over the SCS, this wave is highly baroclinic (Fig. 3) with anticyclonic circulation at $850 \mathrm{hPa}$ and cyclonic circulation at $200 \mathrm{hPa}$. At the central North Pacific, the wave processes an equivalent barotropic structure. As the extratropical wave propagates westward from the central North Pacific to the East Coast of Asia, the vertical structure of this wave gradually tilts westward with height.

\section{Vorticity tendency diagnoses}

\subsection{Relative importance of adiabatic and diabatic forcings}

The 30-60 day vorticity tendencies are diagnosed by computing the three-dimensional streamfunction tendency from Eq. (5). The vorticity tendencies are obtained through the relationship between streamfunction and vorticity. 
a. $200 \mathrm{hPa}$ vort. lag-regr $(\operatorname{lag}=+15$ day $)$

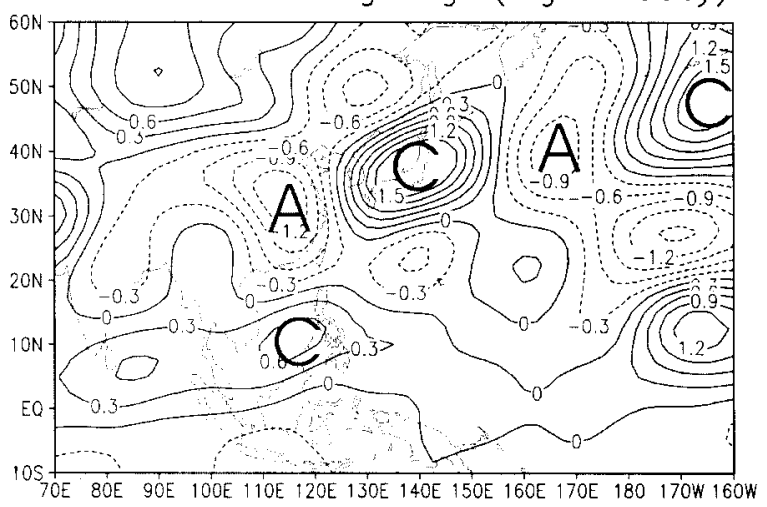

b. $850 \mathrm{hPa}$ vort. lag-regr (lag=+15day)

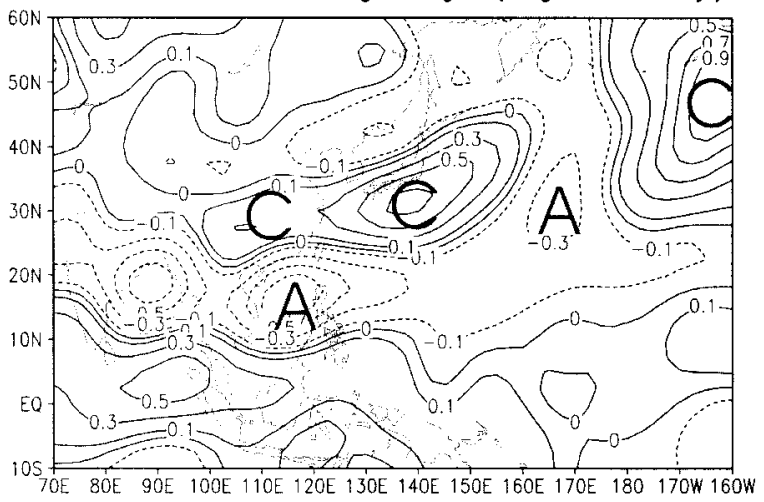

Fig. 3. Lag regression coefficients between the 30-60 day OLR and the 3060 day $200-\mathrm{hPa}$ vorticity (top) and 850 $\mathrm{hPa}$ vorticity (bottom) at lag 15 day. The characters $\mathrm{A}$ and $\mathrm{C}$ indicate anticyclonic and cyclonic circulation, respectively.

Figure 4 shows the lag regression between the 30-60 day OLR index and the 30-60 day OLR, and the vorticity tendencies due to vorticity advection, diabatic heating and the static stability effect. In the present study, the effect of temperature advection appears small (not shown). For simplicity, it is neglected in the following discussion.

At lag 0 day, as the 30-60 day convection over the SCS reaches maximum intensity (Fig. $4 \mathrm{a})$, the vorticity advection induces cyclonic and anticyclonic vorticity to the northwest of the convection and dry belt located between SCS and the equatorial western Pacific, respec- tively. Its main effect is to lead this convection and dry belt to propagate northwestward. The development of the 30-60 day convection is primarily maintained by diabatic heating, which contributes cyclonic and anticyclonic vorticity at the center of the convection and dry belt, respectively (Fig. 4e). The combined effect of vorticity advection and diabatic heating generates cyclonic vorticity on and ahead (northwest) of the 30-60 day convection and anticyclonic vorticity behind (southeast). This situation might favor the convection and cyclonic circulation to develop and propagate northwestward. The cyclonic circulation and convection propagate northwestward during lag 0 day to lag 5 days.

The effect of vertical advection of static stability generally opposes the effect of diabatic heating (Fig. 4i). Over the SCS/WNP where the cyclonic vorticity and convection reaches maximum intensity, the effect of diabatic heating is largely compensated by the vertical advection of static stability associated with the strong upward motion (Fig. 4i). In addition, the decrease of solar radiation associated with the cloud-radiation effect also cancels the effect of latent heating. During lag 0 day to lag 5 days, the effect of vorticity advection and diabatic heating decreases (Figs. $4 \mathrm{~b}$ and $4 \mathrm{f}$ ). The decreasing of vorticity advection and diabatic heating in turn weaken the cyclonic circulation and convection. By lag 15 day, the original cyclonic circulation and convection dissipate as they reach the Asian landmass (Fig. 4d), while the anticyclonic circulation and dry belt quickly develop and propagate to the SCS/WNP. The static stability effect associated with the adiabatic cooling, the decrease of solar radiation due to the cloud-radiation effect (e.g., Lau and Sui 1997), and land surface depletion of the moisture supply (Hsu and Weng 2001) prevent unlimited growth of the 30-60 day oscillation.

While the original tropical convection belt weakens and dissipates, the 30-60 day vorticity and convection redevelop in the extratropical WNP east of Japan $\left(140^{\circ}-160^{\circ} \mathrm{E}\right)$ at lag 5 days (Fig. $4 \mathrm{~b}$ ). It is interesting to note that 30-60 day convection does not develop north of the convection belt where the dry belt and warm SST appear. Investigating the vorticity tendency fields, we find that the diabatic heating induces a negative vorticity tendency north 

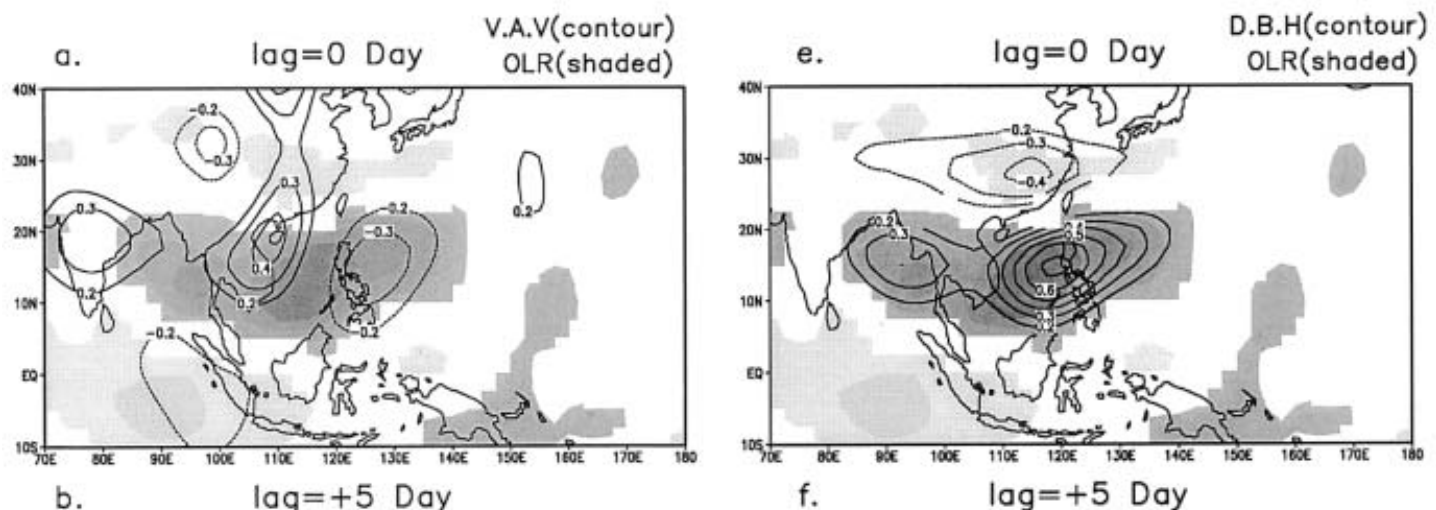

b. $\quad \operatorname{lag}=+5$ Day
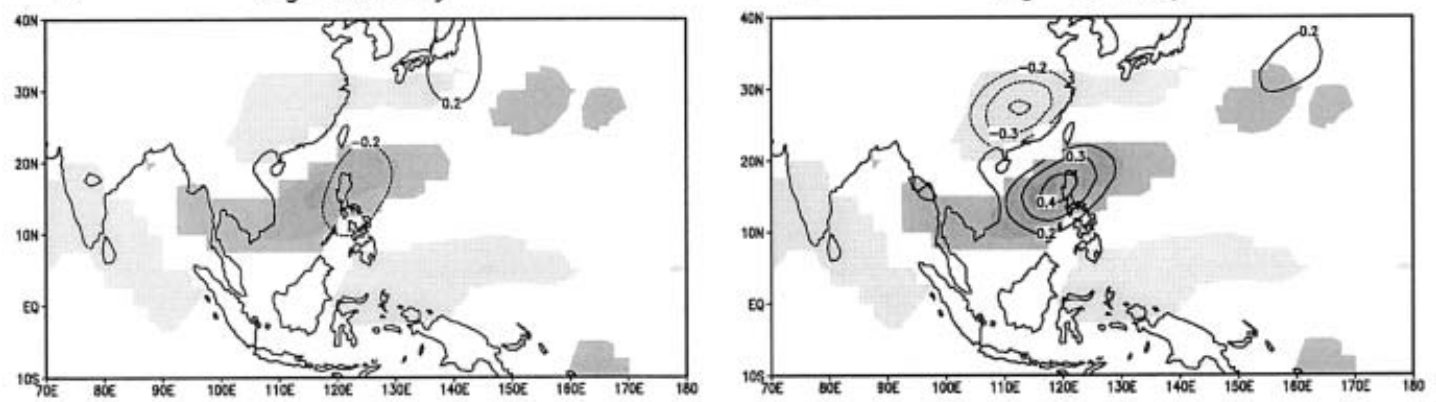

c. $\operatorname{lag}=+10$ Day

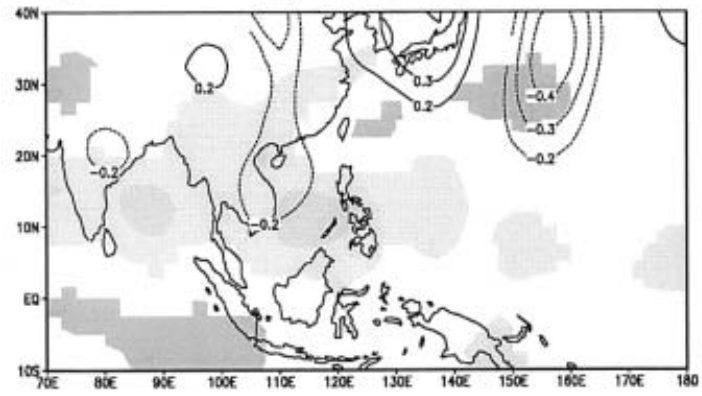

g.

$\operatorname{lag}=+10$ Day

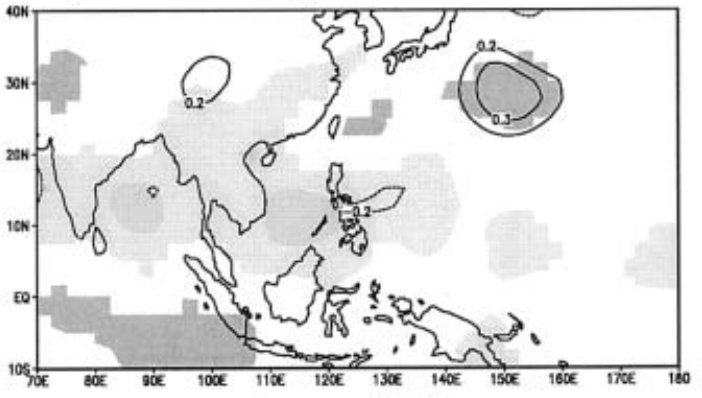

d.

h.

$\log =+15$ Day
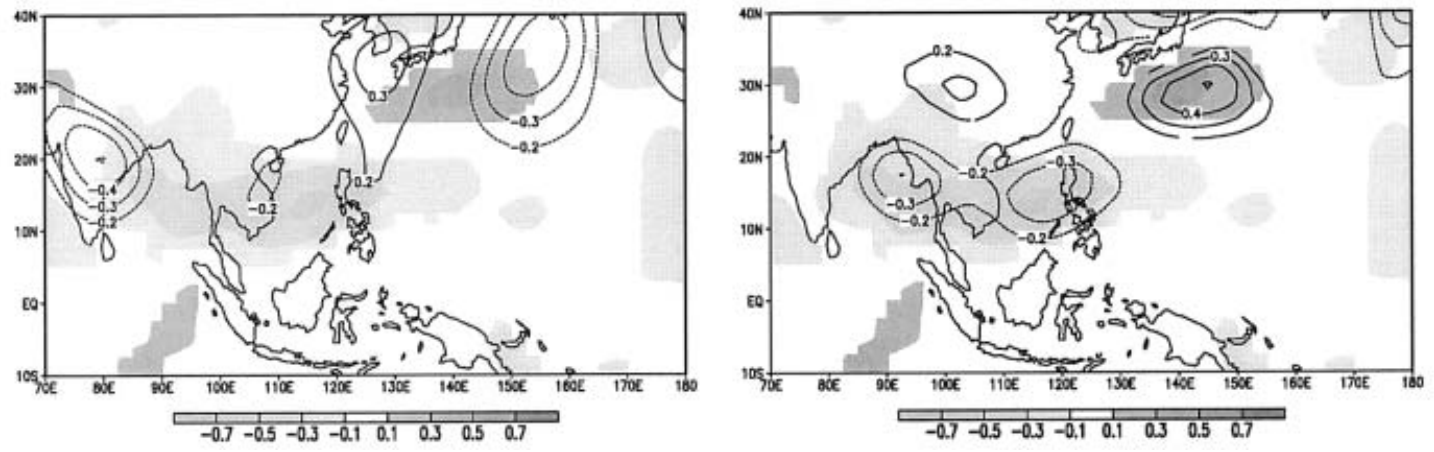

Fig. 4. Same as in Fig. 2 except contours for lag regression coefficients between the 30-60 day OLR at SCS and $850-\mathrm{hPa}$ vorticity tendency due to vorticity advection (left), diabatic heating (middle), and static stability (right). The regression coefficients that are significant at the 0.05 level are shaded or plotted. 

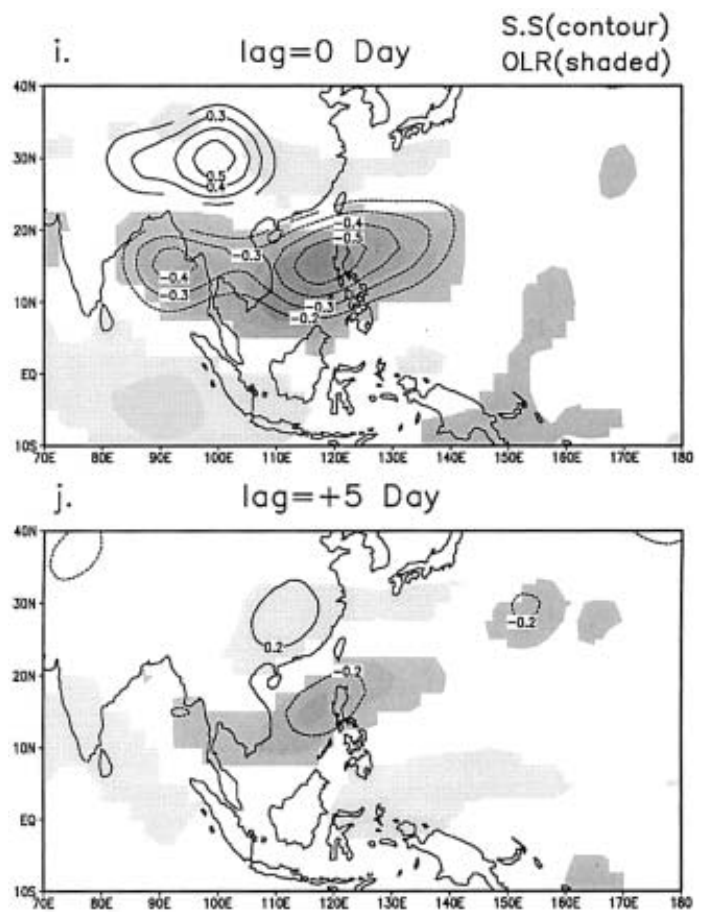

k. $\quad \operatorname{lag}=+10$ Day

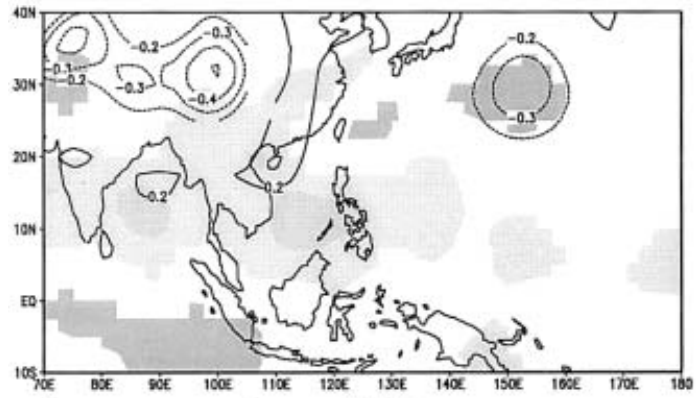

I. $\operatorname{lag}=+15$ Day

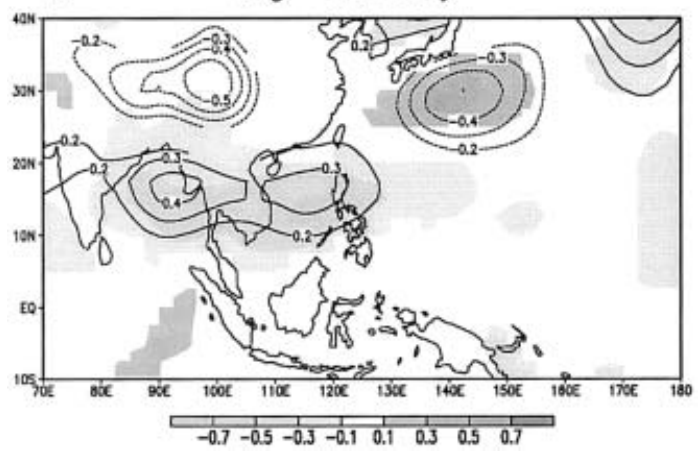

Fig. 4. (continued)

of the convection where the dry belt and warm SST occur (Fig. 4e). On the other hand, prior to the occurrence of convection at lag 5 days, vorticity advection induces the low-level cyclonic vorticity over the region east of Japan $\left(140^{\circ}-\right.$ $160^{\circ} \mathrm{E}$ ) at lag 0 day (Fig. 4a). For planetaryscale waves in mid-latitude ( $\mathrm{f}$ is large), both the low-level and upper-level vorticity advection might impact the vorticity tendency at low levels. This indicates that the establishment of the low-level cyclonic vorticity in the extratropical WNP might be partially contributed by the upper-level cyclonic vorticity advection. The influence of vorticity advection and diabatic heating at different altitude is investigated in the next section, 5.2.

Similar to the northwestward propagation, and development of the 30-60 day oscillation over the SCS, the subsequent northwestward propagation of the new convection in the extratropical WNP is induced by the vorticity advection. It generates cyclonic vorticity to the northwest, and anticyclonic vorticity to the east, of the newly developed convection (Fig. 4c). Diabatic heating plays a dominate role in the development and maintenance of the lowlevel cyclonic vorticity by generating the lowlevel cyclonic vorticity at the center of the convection (Fig. 4g). The combined effect of vorticity advection and diabatic heating leads the convection to propagate and develop northwestward. During the next 5 days, the newly developed cyclonic vorticity and convection pair enhance and propagate northwestward to the south of Japan (Fig. 4d).

Again, the effect of static stability generally opposes the diabatic heating effects (Fig. 4k). This indicates that once the cyclonic circulation is established, the static stability effect associated with the adiabatic cooling inhibits the development of cyclonic circulation. The static stability effect associated with adiabatic cooling (upward motion) or warming (downward motion) inhibits the northwestward propagation or development of cyclonic (anticyclonic) circulation in the tropical and extratropical WNP. This feature is similar to the development of mid-latitude cyclones and blocking anticyclones as diagnosed by Tsou et al. (1987), and Tsou and Smith (1990). However, in the case of midlatitude cyclones and blocking anticyclones in winter, the effect of the static stability is to compensate for the major contribution of vorticity and thermal advection. In the present study, the effect of static stability is to compensate for the effect of diabatic heating. 
vort. \& vort. tend(V.A.V) phase $\mathrm{O}$ vort. \& vort. tend(D.B.H)

a. $200 \mathrm{hPa}$

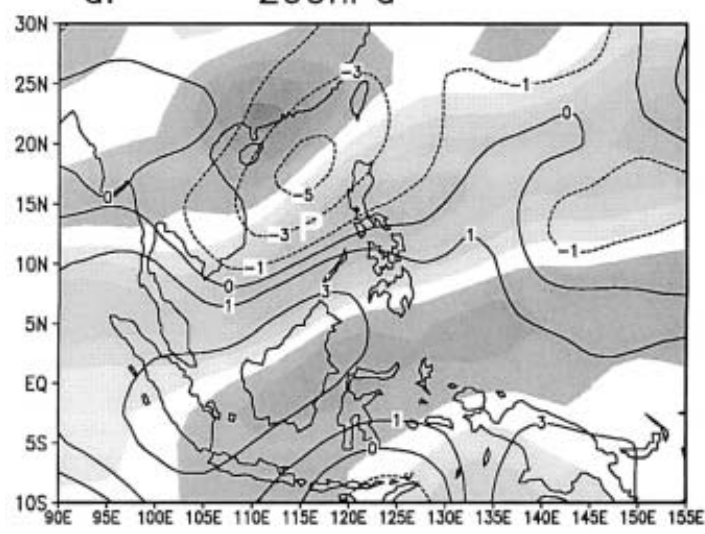

b.

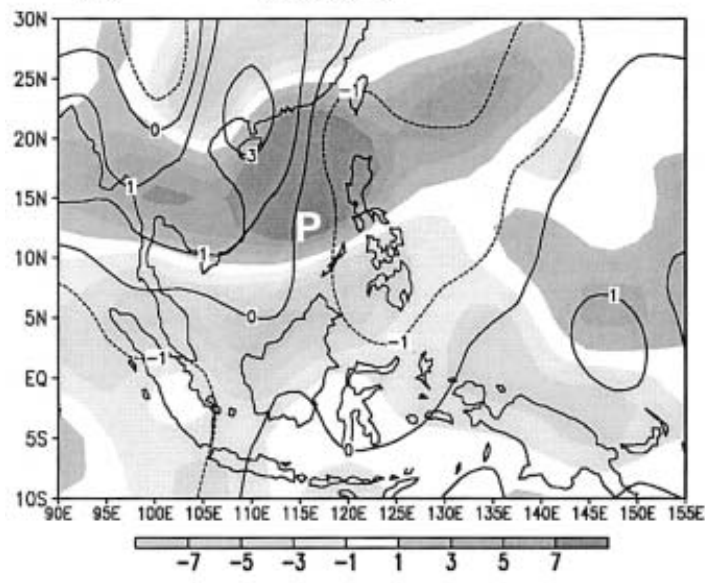

c. $200 \mathrm{hPa}$

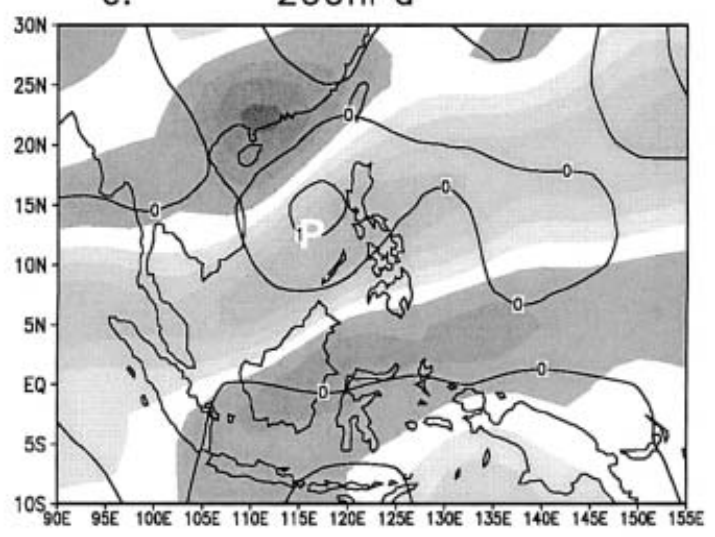

d. $\quad 850 \mathrm{hPa}$

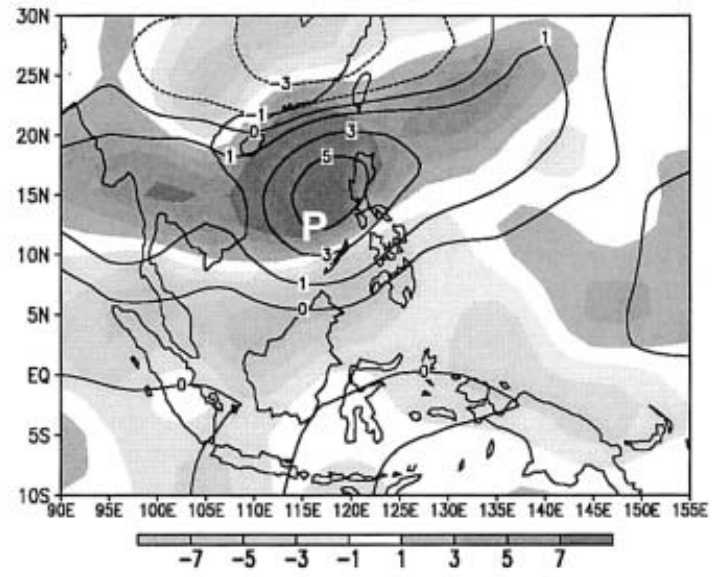

Fig. 5. Composite maps of 30-60 day vorticity (shaded, $10^{-6} \mathrm{~s}^{-1}$ ) and vorticity tendency (contoured, equivalent 24 - $\mathrm{h}$ vorticity change in $10^{-7} \mathrm{~s}^{-1}$ ) contributed by vorticity advection at (a) $200 \mathrm{hPa}$, and (b) $850 \mathrm{hPa}$ at phase 0 . (c, d) same as (a, b) except contours for vorticity tendency due to diabatic heating.

\subsection{Northwestward propagation at upper levels}

The time evolution of the 30-60 day oscillation and vorticity tendencies in the composite study (not shown) is similar to the results of lag-regression analysis (Section 4). Therefore, it is omitted from this section. Instead, we emphasize the vertical structure of 30-60 day oscillation. Figure 5 shows the composite vorticity fields and vorticity tendencies due to vorticity advection and diabatic heating at $200 \mathrm{hPa}$ and $850 \mathrm{hPa}$ at phase 0 . As depicted in the lagregression analysis, the wave train structure from the tropical WNP to SCS at $850 \mathrm{hPa}$ and
$200 \mathrm{hPa}$ are in opposite phase (Figs. 5a and $5 b)$. Vorticity advection over the SCS induces cyclonic vorticity to the northwest of cyclonic vorticity center at $850 \mathrm{hPa}$ and anticyclonic vorticity to the northwest of anticyclonic vorticity center at $200 \mathrm{hPa}$ (Figs. 5a and 5b). This indicates that the wave train at the low and upper levels would propagate northwestward with a baroclinic wave structure. Diabatic heating contributes to the development and maintenance of the 30-60 day convection by generating deep-layer cyclonic vorticity over the SCS where the strongest convection occurs (Figs. 5c and 5d). 


\section{vort. \& vort. tend(V.A.V) phase $\mathrm{O}$ vort. \& vort. tend(D.B.H)}

a. $\quad y-z$ section

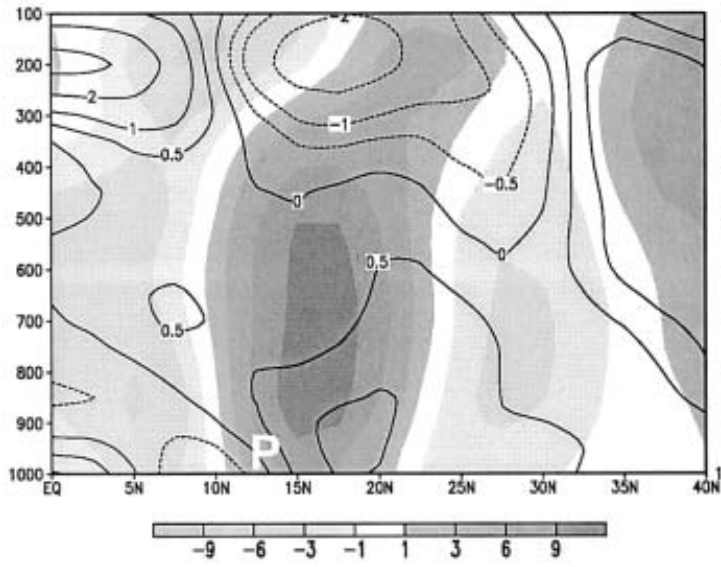

b. $y-z$ section

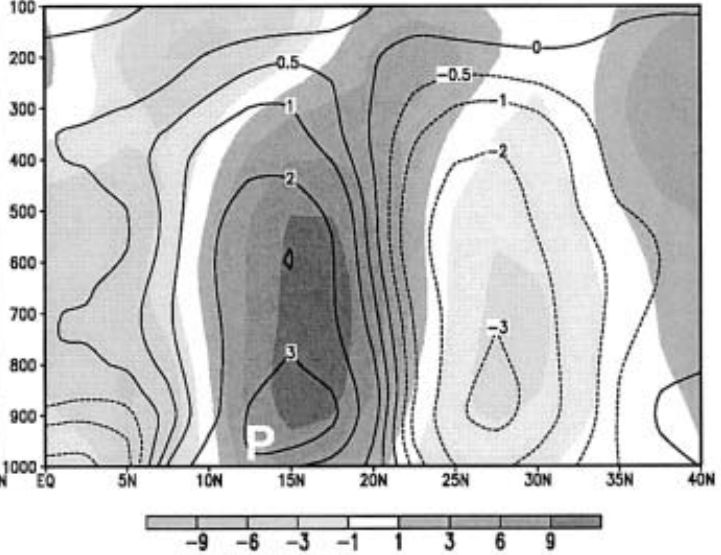

Fig. 6. Meridional cross sections along $100^{\circ}-120^{\circ} \mathrm{E}$ of the composite $30-60$ day vorticity (shaded, $10^{-6} \mathrm{~s}^{-1}$ ) and vorticity tendency (contoured, equivalent $24-\mathrm{h}$ vorticity change in $10^{-7} \mathrm{~s}^{-1}$ ) due to (a) vorticity advection, and (b) diabatic heating at phase 0 .

The wave train at the upper and low levels can also be identified in the vertical-meridional cross section along $120-140^{\circ} \mathrm{E}$ (Fig. 6a). In addition, a local meridional circulation is accompanied by the 30-60 day oscillation with strong upward motion at SCS/WNP and downward motion at northwest and southeast of the convection (Fig. 6a). Vorticity advection generates cyclonic vorticity to the north of the precipitation belt $\left(15^{\circ} \mathrm{N}\right)$ at the low levels, but induces anticyclonic vorticity at the upper levels, causing the 30-60 day wave train and the local meridional circulation to propagate northwestward. Diabatic heating induces deep-layer cyclonic vorticity over the SCS where the strongest convection occurs (Fig. 6b), and generates deep-layer anticyclonic vorticity to the north of the precipitation belt where the subsidence occurred. Diabatic heating plays an important role in the development and maintenance of the 30-60 day convection and the local meridional circulation.

Figure 7 depicts the zonal-vertical crosssection of the 30-60 day vorticity and the vorticity tendency contributed by the vorticity advection and diabatic heating at $30^{\circ} \mathrm{N}$ over the North Pacific at phase 4. Similar to the tropical ISO, this northwestward propagation of the $30-60$ day oscillation at $30^{\circ} \mathrm{N}$ is also contributed by the vorticity advection. However, the vertical structure of the 30-60 day oscillation over the SCS and extratropical WP are significantly different (compare Fig. $6 \mathrm{a}$ and Fig. $7 \mathrm{a})$. At $30-35^{\circ} \mathrm{N}$, where the coriolis parameter becomes large, the influence of upper-level vorticity advection extends down to the low levels (Fig. 7a). It is suggested that the upper-level circulation might play an important role on the establishment of the low-level cyclonic circulation in the extratropical WNP. East of $140^{\circ} \mathrm{E}$, the vorticity tendency induced by vorticity advection is almost identical at the upper and low levels. The wave processes an equivalent barotropic feature (Fig. 7a). West of $140^{\circ} \mathrm{E}$, the vorticity tendency induced by vorticity advection tilts and increases westward with height (Fig. 7a). Thus, the 30-60 day circulation moves faster at the upper levels than at the low levels. The 30-60 day waves gradually tilt with height as they propagate westward from the central North Pacific to the east coast of Asia.

\subsection{The vorticity advection by rotational and divergent winds}

According to the previous analysis (Sections 5.1 and 5.2), the northwestward propagation of the 30-60 day oscillation is mainly caused by the vorticity advection. To investigate the relative importance of vorticity advection by rotational winds and divergent winds, we divide 
vort. \& vort. tend(V.A.V) phase +4 vort. \& vort. tend(D.B.H)

a. $\quad x-z$ section

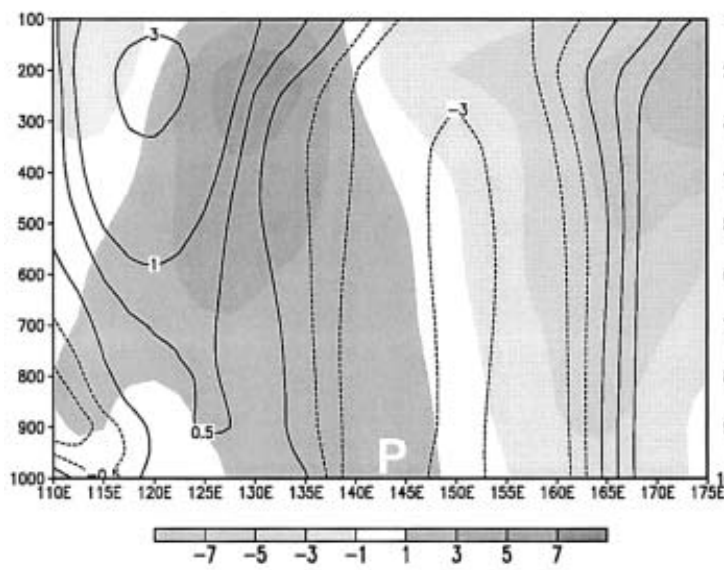

b. $\quad x-z$ section

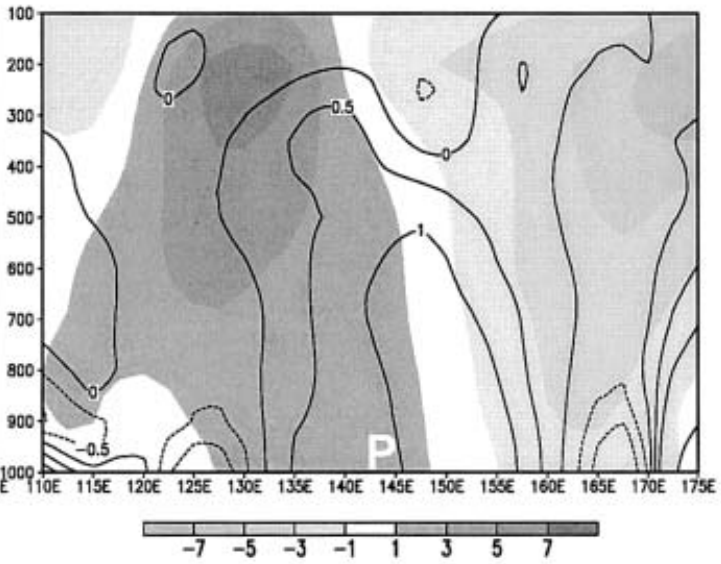

Fig. 7. Zonal cross section along $25^{\circ}-35^{\circ} \mathrm{N}$ of the composite $30-60$ day vorticity (shaded, $10^{-6} \mathrm{~s}^{-1}$ ) and vorticity tendency (contoured, equivalent 24 -h vorticity change in $10^{-7} \mathrm{~s}^{-1}$ ) due to (a) vorticity advection and (b) diabatic heating. The character $P$ indicates the maximum center of precipitation.

\section{Phase 0}

\section{a. $1000 \mathrm{hPa}$ vort. \& rot.wind}

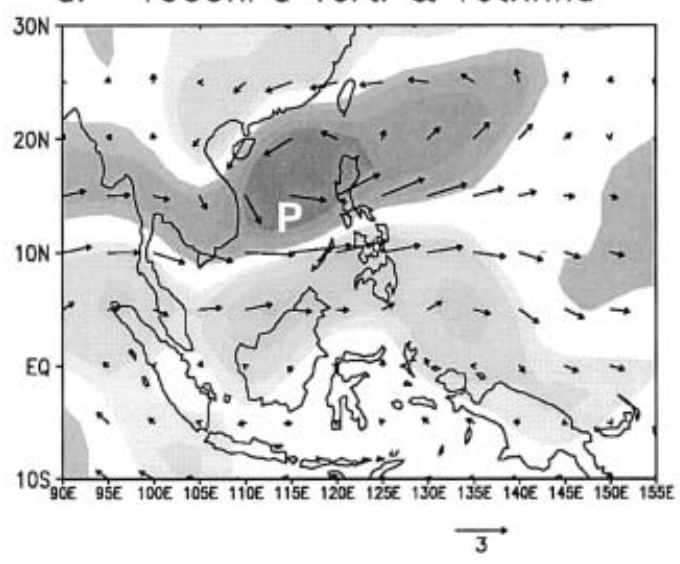

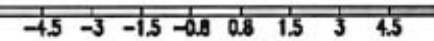

b. $1000 \mathrm{hPa}$ vort. \& dig.wind

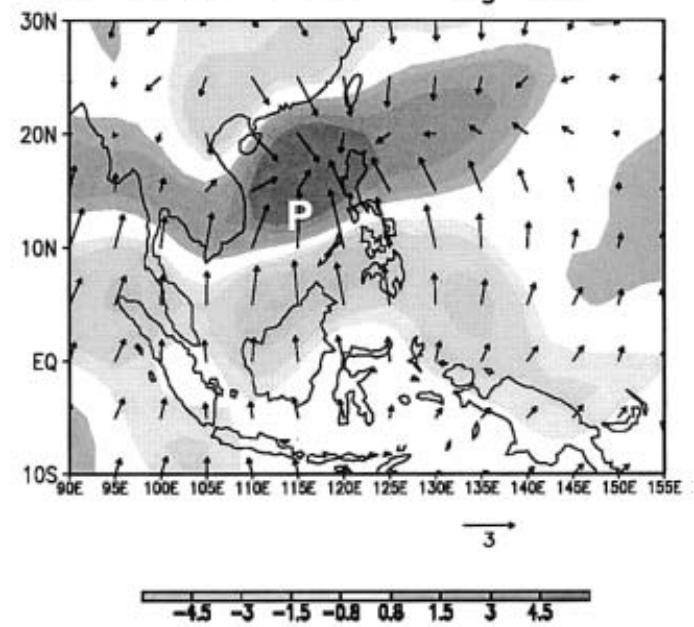

Fig. 8. Composite maps of the 1000-hPa 30-60 day vorticity (shaded, $10^{-6} \mathrm{~s}^{-1}$ ) and (a) rotational wind (vector, $\mathrm{m} \mathrm{s}^{-1}$ ) and (b) divergent winds (vector, $\mathrm{m} \mathrm{s}^{-1}$ ) at phase 0 .

the wind fields into rotational and divergent winds. Figures 8 and 9 depict the composite horizontal distribution of these two wind components superimposed on the vorticity fields; and their relative contribution to the vorticity advection at phase 0 as the convection over the SCS reaches maximum intensity. Apparently, at phase 0 , rotational and divergent winds are comparable at $1000 \mathrm{hPa}$ (Figs. 8a and 8b). Since the rotational winds are generally parallel to the vorticity fields, their main effect is to advect the planetary-scale vorticity at upper and low levels.

In the equatorial region, the low-level con- 


\section{Phase 0}

a. $1000 \mathrm{hPa}$ vort. \& V.A.V (rot.)

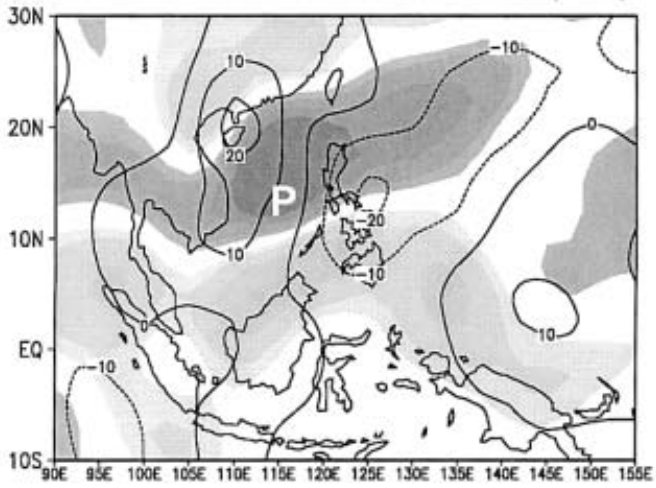

b. $850 \mathrm{hPa}$ vort. \& V.A.V (rot.)

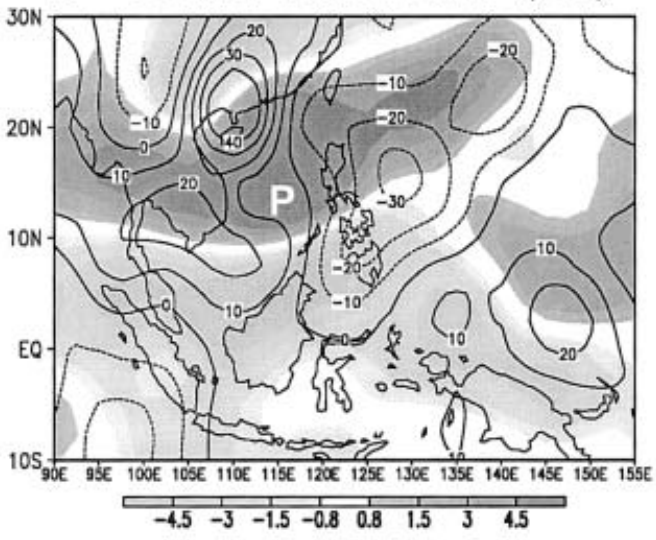

c. $1000 \mathrm{hPa}$ vort. \& V.A.V (dig.)

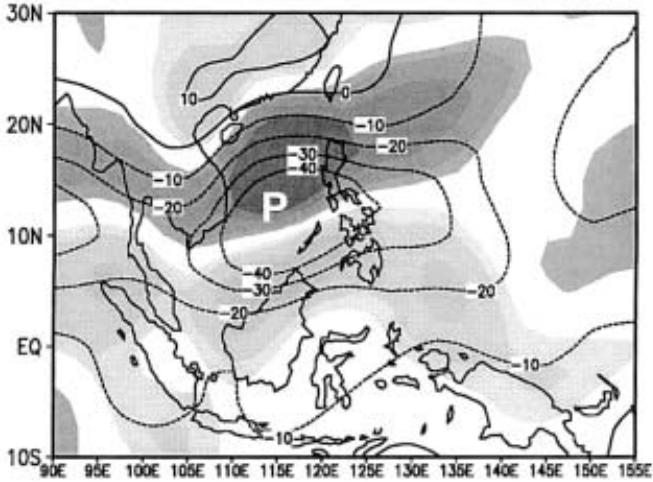

d. $850 \mathrm{hPa}$ vort. \& V.A.V (dig.)

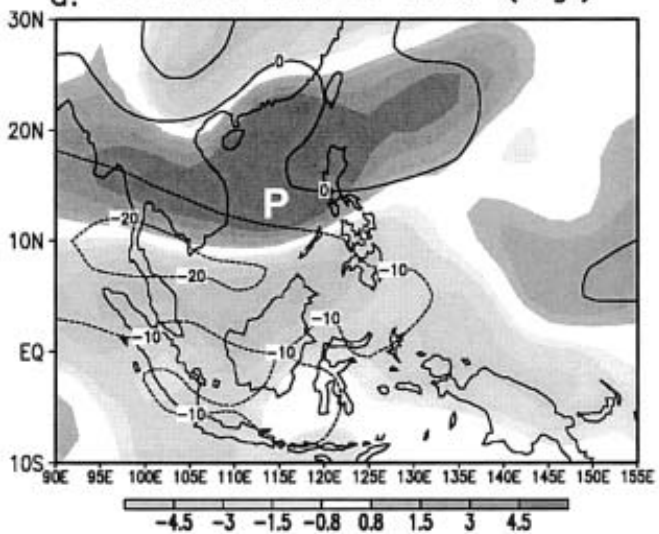

Fig. 9. Composite maps of the vorticity (shaded, $10^{-6} \mathrm{~s}^{-1}$ ) and vorticity advection by rotational winds (contoured, $10^{-12} \mathrm{~s}^{-2}$ ) at (a) $1000 \mathrm{hPa}$, and (b) $850 \mathrm{hPa}$ at phase 0 . (c, d) same as (a, b) except contours for vorticity advection by divergent winds. The character $P$ indicates the maximum center of precipitation.

vergence to the east of $\mathrm{MJO}$ is attributed to the convergence of easterlies and westerly (Hendon and Salby 1994). However, at latitudes between $10-20^{\circ} \mathrm{N}$, the $30-60$ day divergent winds mainly converge in the north-south direction (Fig. 8b). These winds converge into the center of cyclonic vorticity ahead (northwest) of the deep convection (Fig. 8b). This finding is in agreement with the recent study by Lawrence and Webster (2002). Such a feature implies that the surface frictional convergence associated with the cyclonic vorticity to the northwest of the convection provides favorable conditions for the 30-60 day convection to develop northwestward. Meanwhile, the divergent and rotational winds advect cyclonic vorticity to the northwest of the cyclonic circulation (Figs. 9a and $9 \mathrm{~b}$ ), causing the cyclonic circulation to propagate northwestward. Thus, the surface frictional effect associated with the cyclonic circulation enhances the low-level convergence at the cyclonic vorticity center to the northwest of the convection, causing the 30-60 day convection to develop northwestward. At the same time, the cyclonic vorticity advection ahead of the cyclonic vorticity center at the low-level leads the low-level cyclonic vorticity to propagate northwestward. The low-level cyclonic center shifts to the northwest of the convection as the circulation and convection propagate northwestward simultaneously.

The importance of divergent winds is con- 
fined to the surface. At $850 \mathrm{hPa}$, vorticity advection by the rotational winds is larger than that by the divergent winds (Figs. $9 \mathrm{~b}$ and $9 \mathrm{~d}$ ). Thus, the upper-level vorticity advection is mainly contributed by the rotational winds.

\section{Summary and discussion}

The physical mechanisms responsible for the northwestward and northward propagation of the 30-60 day oscillation in the Asian Monsoon region are still in debate (e.g., Webster 1983a; Ferranti et al. 1999). A three-dimensional streamfunction equation applicable to the planetary-scale waves is derived from the scale analysis study by Charney (1963) to investigate the mechanisms responsible for the northward development and propagation of the 30-60 day oscillation in the WNP. The vorticity tendency is obtained through the relationship between streamfunction and vorticity.

The role of each forcing mechanisms on the northwestward propagation of the 30-60 day oscillation in the tropical WNP is illustrated in Fig. 10. In the beginning of northwestward propagation, a Rossby wave train, which may be generated by the mechanism proposed by Wang and Xie (1997), appears at upper and low levels with opposite phase (Fig. 10a). The vorticity advection contributes cyclonic (anticyclonic) vorticity to the northwestward of the 30-60 day cyclonic (anticyclonic) circulation at the low (upper) levels (Fig. 10a), leading the 30-60 day circulation at both levels to propagate northwestward with a baroclinic structure (Fig. 10b). Meanwhile, the surface frictional convergence at the center of the cyclonic circulation to the northwest of the 30-60 day convection, induces the convection to develop and propagate northwestward (Fig. 10b) in consistent with the recent study by Lawrence and Webster (2002). It is interesting to note that surface frictional convergence alone is not sufficient to interpret the propagation of the 30-60 day circulation at the upper and low levels. The combined effects of vorticity advection and surface frictional-diabatic heating causes the 30-60 day convection and circulation pair to simultaneously develop and propagate northwestward on the warm ocean surface. Both internal and external forcing play an important role on the northward development and propagation of the 30-60 day.

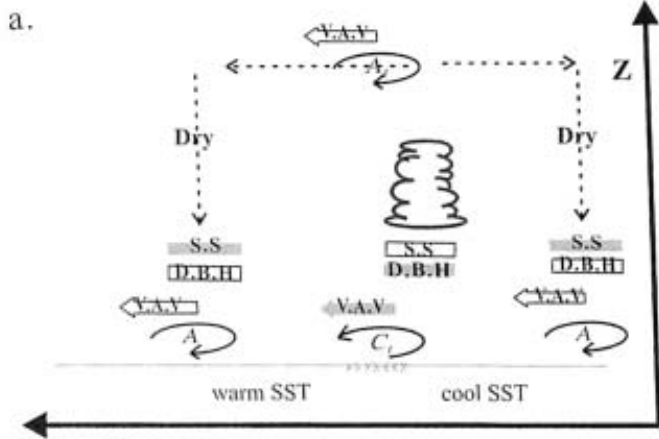

NW

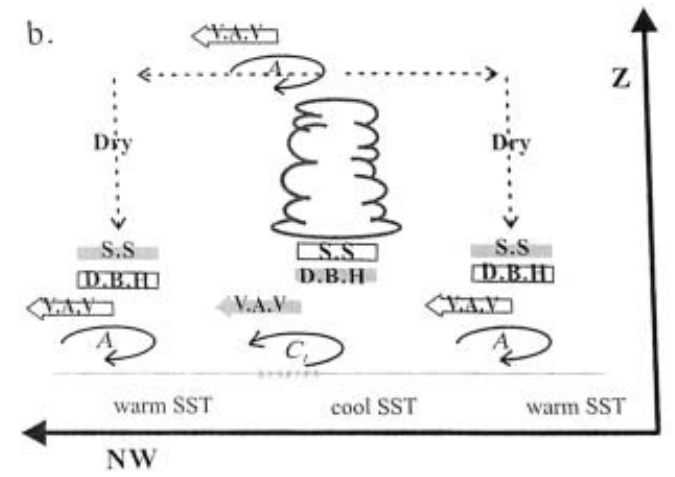

c.

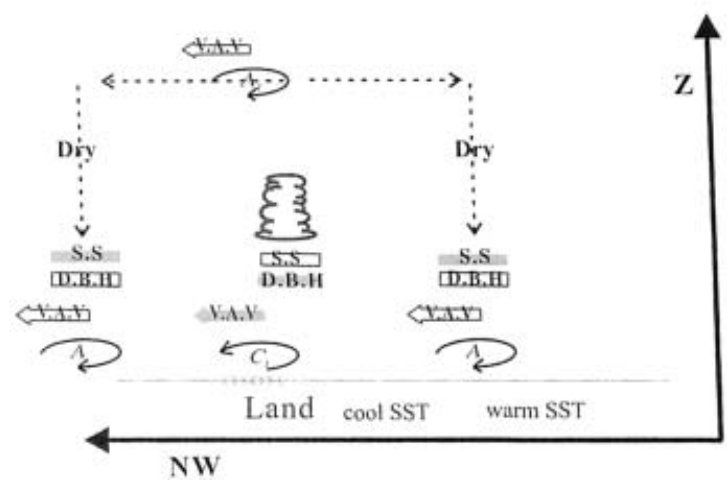

Fig. 10. Schematic diagram illustrates the vertical structures and northwestward development and propagation of 30-60 day oscillation for (a) development, (b) mature, and (c) dissipation stages. The bold streamlines with characters $\mathrm{A}$ and $\mathrm{C}$ indicate anticyclonic and cyclonic circulations, respectively. Dark (light) arrows indicate positive (negative) vorticity advection due to V.A.V (vorticity advection). Dark (light) strips indicate positive (negative) vorticity advection due to D.B.H (diabatic heating) and S.S. (static stability effect). The symbols " $x$ " indicate surface friction. 
Diabatic heating plays a dominate role on the development and maintenance of the low-level cyclonic vorticity by generating cyclonic vorticity at the center of the convection (Figs. 10a and $10 \mathrm{~b}$ ). Once the convection fully develops (Fig. 10b), the static stability effect associated with adiabatic cooling (Tsou et al. 1987), the decrease of solar radiation due to the cloudradiation effects (Lau and Sui 1997), and the depletion of moisture supply by land-surfaces (Hsu and Weng 2001) prevent any further development of the 30-60 day oscillation (Fig. 10c).

A 30-60 day wave train appears in the region from SCS to the extratropical North $\mathrm{Pa}-$ cific 15-days after the convection reaches maximum intensity over the SCS. This feature is consistent with the observational results of Kawamura et al. (1996). The upper-level vorticity advection might play an important role on the establishment of the low-level cyclonic vorticity of this extratropical 30-60 day oscillation, while the ocean may play a passive role on the development of the 30-60 day oscillation in the extratropical WNP. Once the low-level cyclonic circulation and convection establish, they propagate northwestward to the South of Japan and enhance. The main processes and mechanisms responsible for the northwestward propagation of the 30-60 day oscillation in the extratropical WNP are similar to the process proposed for the tropical WNP (Fig. 10) except that in the extratropical North Pacific as the coriolis parameter becomes large; the influence of upperlevel vorticity advection extends down to the low levels.

This study demonstrates the importance of internal and external forcing on the northward and northwestward development and propagation of the 30-60 day oscillation in the tropical and extratropical WNP. The ocean may play a passive role on the development of the 30-60 day oscillation in the extratropical WNP. In agreement with the suggestion by KemballCook and Wang (2001), coupled models may be required to simulate adequately the northward propagation of ISO in the Asian monsoon region.

\section{Acknowledgements}

The authors wish to thank two anonymous reviewers for their valuable comments and constructive suggestions. This research was sponsored by the National Taiwan Normal University and the National Science Council of Taiwan under grant NSC 91-2111-M-003-005.

\section{References}

Charney, J.G., 1963: A note on the large-scale motions in the tropics. J. Atmos. Sci., 20, 607609.

Chen, T.-C. and J.-M. Chen, 1995: An observational study of the South China Sea monsoon during the 1979 summer: Onset and life cycle. Mon. Wea. Rev., 123, 2295-2318. and M. Murakami, 1988: The 30-50 day variation of convective activity over the western Pacific Ocean with emphasis on the northwestern region. Mon. Wea. Rev., 116, 892-906.

-, M.-C. Yen, and S.-P. Weng, 2000: Interaction between the summer monsoons in East Asia and South China Sea: Intraseasonal monsoon modes. J. Atmos. Sci., 57, 1373-1392.

Daubechies, I., 1988: Orthonormal bases of compactly supported wavelets. Commun. Pure Appl. Math., 41, 909-996.

Ferranti, L., J.M. Slingo, T.N. Palmer, and B.J. Hoskins, 1999: The effect of land-surface feedbacks on the monsoon circulation. Quart. J. Roy. Meteor. Soc., 125, 1527-1550.

Gill, A.E., 1980: Some simple solutions for heatinduced tropical circulation. Quart. J. Roy. Meteor. Soc., 106, 447-462.

Goswami, B.N. and J. Shukla, 1984: Quasi-periodic oscillations in a symmetrical general circulation model. J. Atmos. Sci., 41, 20-37.

Hendon, H.H. and M.L. Salby, 1994: The life cycle of the Madden-Julian oscillation. J. Atmos. Sci., 51, 2225-2237.

Hsu, H.H. and C.H. Weng, 2001: Northwestward propagation of the intraseasonal oscillation in the western north Pacific during the boreal summer: Structure and mechanism. J. Climate, 14, 3834-3850.

Jiang, X., T. Li, and B. Wang, 2004: Structures and mechanisms of the northward propagating boreal summer intraseasonal oscillation. J. Climate, 17, 1022-1039.

Kalnay, E., M. Kanamitsu, R. Kistler, W. Collins, D. Deaven, L. Gandin, M. Iredell, S. Saha, G. White, J. Woollen, Y. Zhu, A. Leetmaa, B. Reynolds, M. Chelliah, W. Ebisuzaki, W. Higgins, J. Janowiak, K.C. Mo, C. Ropelewski, and J. Wang, 1996: The NCEP/NCAR 40-Year Reanalysis Project. Bull. Amer. Meteor. Soc., 77, 437-471.

Kawamura, R., T. Murakami, and B. Wang, 1996: 
Tropical and mid-latitude 45-day perturbations over the western Pacific during the northern summer. J. Meteor. Soc. Japan, 74, 876-890.

Kemball-Cook, S.R. and B. Wang, 2001: Equatorial waves and air-sea interaction in the boreal summer intraseasonal oscillation. J. Climate, 14, 2923-2942.

Krishnamurti, T.N. and D. Subrahmanyam, 1982: The 30-50 day mode at $850 \mathrm{mb}$ during MONEX. J. Atmos. Sci., 39, 2088-2095.

, P.K. Jayakumar, J. Sheng, N. Surgi, and A. Kumar, 1985: Divergent circulations on the 30 to 50 day time scale. J. Atmos. Sci., 42, 364375.

Lau, K.-M. and P.H. Chan, 1986: Aspects of the 4050 day oscillation during the northern summer as inferred from outgoing longwave radiation. Mon. Wea. Rev., 114, 1354-1367.

and C.H. Sui, 1997: Mechanisms of shortterm sea surface temperature regulation: $\mathrm{Ob}$ servations during TOGA COARE. J. Climate, 10, 465-472.

Lawrence, D.M. and P.J. Webster, 2002: The boreal summer intraseasonal oscillation: Relationship between northward and eastward movement of convection. J. Atmos. Sci., 59, 1593-1606.

Liebmann, B. and C.A. Smith, 1996: Description of a complete (interpolated) outgoing longwave radiation dataset. Bull. Amer. Meteor. Soc., 77, 1275-1277.

Newman, M., P.D. Sardeshmukh, and J.W. Berg- man, 2000: An assessment of the NCEP, NASA, and ECMWF reanalyses over the tropical west Pacific warm pool. Bull. Amer. Meteor. Soc., 81, 41-48.

Reynolds, R.W. and T.M. Smith, 1994: Improved global sea surface temperature analyses using optimum interpolation. J. Climate, 7, 929-948.

Tsou, C.H., P.J. Smith, and P.P. Pauley, 1987: A comparison of adiabatic and diabatic forcing in an intense extratropical cyclone system. Mon. Wea. Rev., 115, 763-786.

and - 1990: The role of synoptic/ planetary-scale interactions during the development of a blocking anticyclone. Tellus, 42, 174-193.

Wang, B. and X. Xie, 1996: Low-frequency equatorial waves in vertically sheared zonal flow. Part I: Stable waves. J. Atmos. Sci., 53, 449-467. and -, 1997: A model for the boreal summer intraseasonal oscillation. J. Atmos. Sci., 54, 72-86.

Webster, P.J., 1983a: Mechanism of monsoon low frequency variability: Surface hydrological effects. J. Atmos. Sci., 40, 2110-2124. , 1983b: The large-scale structure of the tropical atmosphere. In B.J. Hoskin and R. Pearce (eds.), Large-scale Dynamical Processes in the Atmosphere. Academic Press, 235-276.

Yasunari, T., 1981: Structure of an Indian summer monsoon system with around 40 -day period. $J$. Meteor. Soc. Japan., 59, 336-354. 